\title{
PIXEL-BASED CLASSIFICATION ANALYSIS OF LAND USE LAND COVER USING SENTINEL-2 AND LANDSAT-8 DATA
}

\author{
A. Sekertekin ${ }^{\text {a, } *, \text { A. M. Marangoz }}{ }^{\text {a }}$, H. Akcin ${ }^{\text {a }}$ \\ a BEU, Engineering Faculty, Geomatics Engineering Department 67100 Zonguldak, Turkey - (aliihsan_sekertekin, aycanmarangoz, \\ hakanakcin)@hotmail.com
}

KEY WORDS: Land Use Land Cover, Pixel Based Image Classification, Supervised Classification, Landsat-8 OLI, Sentinel-2 MSI

\begin{abstract}
:
The aim of this study is to conduct accuracy analyses of Land Use Land Cover (LULC) classifications derived from Sentinel-2 and Landsat-8 data, and to reveal which dataset present better accuracy results. Zonguldak city and its near surrounding was selected as study area for this case study. Sentinel-2 Multispectral Instrument (MSI) and Landsat- 8 the Operational Land Imager (OLI) data, acquired on 6 April 2016 and 3 April 2016 respectively, were utilized as satellite imagery in the study. The RGB and NIR bands of Sentinel-2 and Landsat-8 were used for classification and comparison. Pan-sharpening process was carried out for Landsat-8 data before classification because the spatial resolution of Landsat-8 (30m) is far from Sentinel-2 RGB and NIR bands (10m). LULC images were generated using pixel-based Maximum Likelihood (MLC) supervised classification method. As a result of the accuracy assessment, kappa statistics for Sentinel-2 and Landsat- 8 data were 0.78 and 0.85 respectively. The obtained results showed that Sentinel-2 MSI presents more satisfying LULC images than Landsat-8 OLI data. However, in some areas of Sea class Landsat-8 presented better results than Sentinel-2.
\end{abstract}

\section{INTRODUCTION}

Generating LULC image has gained importance in recent years for sustainable land management, landscape ecology and climate related researches (Turner et al., 2001; Pielke et al., 2011). Besides, temporal changes in LULC give us information about proper planning and use of natural resources and their management (Mejía and Hochschild, 2012). Thus, accurate and up to date LULC information is always crucial for a sustainable environment. Furthermore, it is important to monitor LULC changes periodically in fast growing cities since the urban climate can change by the uncontrolled and irregular expansion in the cities.

Remote sensing technology is an effective way to monitor the changes on Earth. Satellite images have been widely used to retrieve LULC images. In particular, various algorithms have been developed, and improved accuracies have been obtained with the advances in remote sensing technologies and sensor types. Sentinel-2 MSI and Landsat-8 OLI are recently operational new generation Earth observation satellites, and thus in this case study these satellites were selected as data sources. Many studies have been conducted using only Sentinel-2 data, only Landsat- 8 data and both together, and so many methods have been applied to investigate which method gives better the accuracy results (Elhag \& Boteva, 2016; Liu et al., 2015; Jia et al., 2014; Pirotti et al., 2016; Topaloglu et al., 2016; Marangoz et al., 2017). The aim of this study is to generate LULC images from Sentinel-2 MSI and Landsat-8 OLI data using pixel-based MLC supervised classification method, and to reveal which LULC image presents better accuracy results.

\section{STUDY AREA}

The study area, Zonguldak is located on the coast of Western Black Sea region of Turkey (Figure 1). Zonguldak has rugged terrain and it is one of the main coal mining areas in the world. Furthermore, it is an important industrial region including four thermal power plants, and one of the biggest iron and steel plant in Europe. Thus it is important to monitor LULC changes in this region.

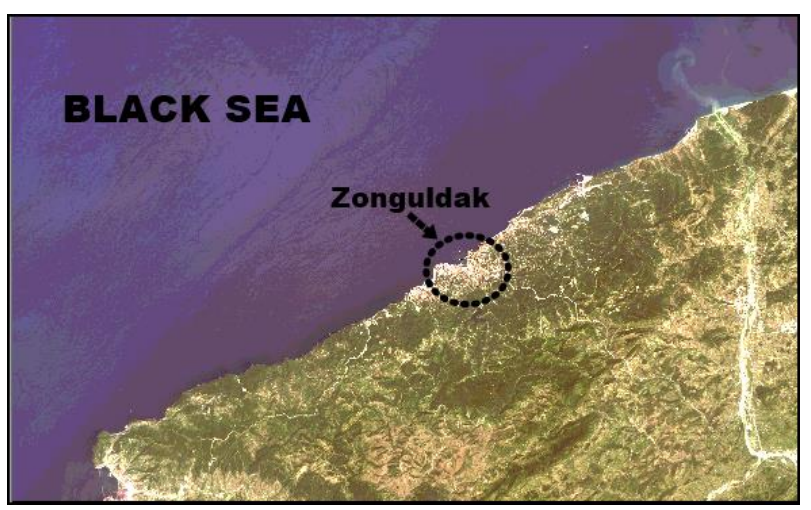

Figure 1. Study Area Zonguldak, Turkey (Landsat-8 RGB)

\section{MATERIAL AND METHOD}

Sentinel-2 MSI and Landsat-8 OLI data, acquired on 6 April 2016 and 3 April 2016 respectively, were used as satellite imagery in the study. Common bands of those two dataset namely Red (R), Green (G), Blue (B) and Near Infrared (NIR) were used in the process of classification. The spectral bands and Ground Sampling Distance (GSD) values of both satellites are as presented in Table 1 .

\begin{tabular}{|c|c|c|c|c|c|}
\hline \multicolumn{3}{|c|}{ Landsat-8 Specifications } & \multicolumn{3}{c|}{ Sentinel-2 Specifications } \\
\hline Bands & $\begin{array}{c}\text { Wavelength } \\
(\text { micrometers })\end{array}$ & $\begin{array}{c}\text { GSD } \\
(\mathrm{m})\end{array}$ & Bands & $\begin{array}{c}\text { Central } \\
\text { Wavelength } \\
(\mu \mathrm{m})\end{array}$ & $\begin{array}{c}\text { GSD } \\
(\mathrm{m})\end{array}$ \\
\hline
\end{tabular}

* Corresponding author 


\begin{tabular}{|c|c|c|c|c|c|}
\hline Band 1 & $0.43-0.45$ & 30 & Band 2 & 0.490 & \multirow{4}{*}{10} \\
\hline Band 2 & $0.45-0.51$ & 30 & Band 3 & 0.560 & \\
\hline Band 3 & $0.53-0.59$ & 30 & Band 4 & 0.665 & \\
\hline Band 4 & $0.64-0.67$ & 30 & Band 8 & 0.842 & \\
\hline Band 5 & $0.85-0.88$ & 30 & Band 5 & 0.705 & \multirow{6}{*}{20} \\
\hline Band 6 & $1.57-1.65$ & 30 & Band 6 & 0.740 & \\
\hline Band 7 & $2.11-2.29$ & 30 & Band 7 & 0.783 & \\
\hline Band 8 & $0.50-0.68$ & 15 & Band 8a & 0.865 & \\
\hline Band 9 & $1.36-1.38$ & 30 & Band 11 & 1.610 & \\
\hline Band 10 & $10.60-11.19$ & 30 & Band 12 & 2.190 & \\
\hline Band 11 & $11.50-12.51$ & 30 & Band 1 & 0.443 & \multirow{3}{*}{60} \\
\hline & & & Band 9 & 0.945 & \\
\hline & & & Band 10 & 1.375 & \\
\hline
\end{tabular}

Table 1. Spectral bands and GSD values of datasets

Before the image classification process, pre-processing steps for satellite images were implemented. RGB and NIR bands of two datasets are common and thus these four bands were considered for layer stacking. For Landsat- 8 data, band 2, band 3 band 4 and band 5 were layer stacked and then clipped so as to include the study area. After clipping, Landsat-8 pan-sharpened image was created using High Pass Filtering (HPF) pan sharp algorithm in ERDAS software package. Pan-sharpening process was used to make familiar the GSD of two datasets. For Sentinel-2 data, the same pre-processing steps were implemented except for pansharpening using SNAP software developed by European Space Agency (ESA) and its partners.

Five general LULC classes including Water Body, Settlement Area, Bare Land, Forest and Vegetation were utilized in this case study. For each LULC class, at least 15 samples were collected and used for the classification of both images in ERDAS. Same training samples were used for both data sets.

MLC is the most common classification method introduced in the literature (Benedictsson et al., 1990), and uses the statistics for each class in each band as a normally distributed function and computes the likelihood of a given pixel belongs to a specific category based on the following equation (Elhag \& Boteva, 2016):

$$
\mathrm{g}_{\mathrm{i}}(\mathrm{x})=\ln \mathrm{p}\left(\mathrm{w}_{\mathrm{i}}\right)-\frac{1}{2} \ln |\Sigma \mathrm{i}|-\frac{1}{2}\left(\mathrm{x}-\mathrm{m}_{\mathrm{i}}\right)^{\mathrm{T}} \Sigma \mathrm{i}^{-1}\left(\mathrm{x}-\mathrm{m}_{\mathrm{i}}\right)
$$

Where;

$\mathrm{i}=$ class

$\mathrm{x}=\mathrm{n}$-dimensional data (where $\mathrm{n}$ is the number of bands)

$\mathrm{p}\left(\mathrm{w}_{\mathrm{i}}\right)=$ probability that class $\mathrm{w}_{\mathrm{i}}$ occurs in the image and is assumed the same for all classes

$|\Sigma i|=$ determinant of the covariance matrix of the data in class $\mathrm{w}_{\mathrm{i}}$ $\Sigma \mathrm{i}^{-1}=$ its inverse matrix

$\mathrm{m}_{\mathrm{i}}=$ mean vector.

\section{RESULTS}

Classified Landsat-8 and Sentinel-2 images are presented in Figure 2. Due to the spatial resolution of the datasets, general classes namely Water Body, Settlement Area, Bare Land, Forest and Vegetation were considered as LULC classes.
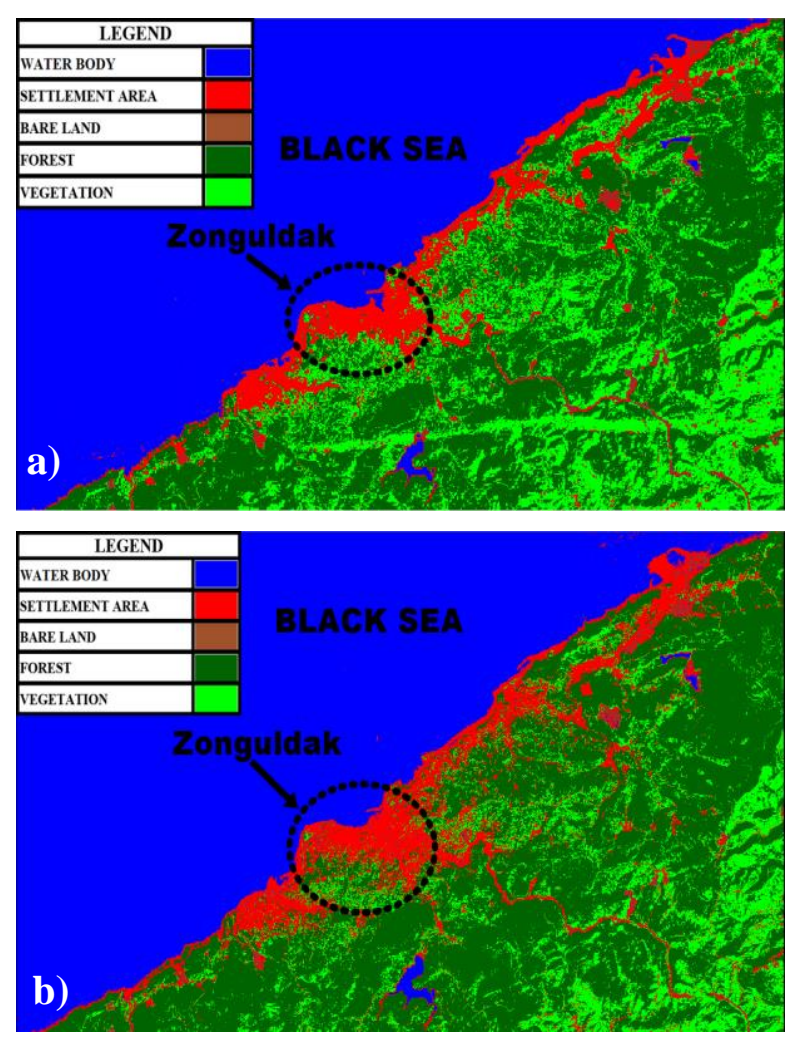

Figure 2. LULC images of the study area; a) Landsat- 8 derived LULC, b) Sentinel-2 derived LULC

After generating LULC images, accuracy assessment for both images was carried out using 460 stratified random points. In Table 2, accuracy assessment report is presented. As a result of stratified random point evaluation Sentinel-2 derived LULC image have higher kappa value (0.85) and overall accuracy $(88.74 \%)$ than Landsat- 8 derived LULC. This is just a general evaluation, thus these results can vary when using different classification methods and statistics for accuracy assessment.

\begin{tabular}{|c|c|c|c|c|}
\hline & \multicolumn{2}{|c|}{ Landsat-8 LULC } & \multicolumn{2}{c|}{ Sentinel-2 LULC } \\
\hline & $\begin{array}{c}\text { User's } \\
\text { Accuracy }\end{array}$ & $\begin{array}{c}\text { Producer's } \\
\text { Accuracy }\end{array}$ & $\begin{array}{c}\text { User's } \\
\text { Accuracy }\end{array}$ & $\begin{array}{c}\text { Producer's } \\
\text { Accuracy }\end{array}$ \\
\hline Water Body & 97.78 & 99.44 & 100.00 & 100.00 \\
\hline $\begin{array}{c}\text { Settlement } \\
\text { Area }\end{array}$ & 70.37 & 82.61 & 82.61 & 90.48 \\
\hline Bare Land & 43.75 & 36.84 & 50.00 & 30.00 \\
\hline Forest & 80.65 & 78.13 & 82.71 & 92.44 \\
\hline Vegetation & 75.58 & 72.22 & 84.93 & 72.94 \\
\hline $\begin{array}{c}\text { Overall } \\
\text { Accuracy }\end{array}$ & \multicolumn{2}{|c|}{$\mathbf{8 3 . 9 1 \%}$} & \multicolumn{2}{c|}{$\mathbf{8 8 . 7 4 \%}$} \\
\hline $\begin{array}{c}\text { Kappa } \\
\text { Coefficient }\end{array}$ & \multicolumn{2}{|c|}{$\mathbf{0 . 7 8}$} & \multicolumn{2}{c|}{$\mathbf{0 . 8 5}$} \\
\hline
\end{tabular}

Table 2. Accuracy assessment results for LULC images

\section{CONCLUSION}

In this study, LULC images were obtained from Landsat-8 and Sentinel-2 data sets using pixel based MLC method, and the results were evaluated using accuracy assessment by 400 random points. As a result of accuracy assessment, Overall accuracy and Kappa coefficient for Landsat-8 derived LULC and Sentinel-2 derived LULC were $83.91 \%, 0.78$ and $88.74 \%, 0.85$ respectively. Although it seems that Sentinel-2 represents LULC better than Landsat- 8 generally, this situation can change if different classification methods and statistics are used. Although 
overall accuracy for Sentinel-2 derived LULC is better than Landsat- 8 derived LULC. If some of the parts of the LULC images are considered, pan-sharpened Landsat- 8 can offer better results for some areas in Sea class than Sentinel-2 as it is clear from Figure 2.

LULC images are crucial for fast grown cities in order to understand the dynamics of urban growth. Satellite imagery is one of the main resources to monitor the changes on Earth, especially new generation Earth observation satellites such as Landsat- 8 and Sentinel-2 can be obtained freely, and LULC images can be produced in a good temporal resolution. Temporal analyses of LULC help city planners and decision makers to improve the standards of the cities.

\section{REFERENCES}

Benedictsson, J. A., Swain, P. H., and Ersoy, O. K., 1990. Neural network approaches versus statistical methods in classification of multisource remote sensing data. IEEE Transactions on Geoscience and Remote Sensing, 28, 540-551.

Elhag, M., Boteva, S., 2016. Mediterranean land use and land cover classification assessment using high spatial resolution data. In IOP Conference Series: Earth and Environmental Science, Vol. 44, No. 4, p. 042032.

Hale Topaloglu, R., Sertel, E., \& Musaoglu, N., 2016. Assessment of Classification Accuracies of SENTINEL-2 and LANDSAT-8 Data for Land Cover/Use Mapping. In: International Archives of the Photogrammetry, Remote Sensing and Spatial Information Sciences, Prague, Czech Republic, Vol: XLI-B8, pp. 1055-1059.

Jia, K., Wei, X., Gu, X., Yao, Y., Xie, X., \& Li, B., 2014. Land cover classification using Landsat 8 operational land imager data in Beijing, China. Geocarto International, 29(8), 941-951.

Liu, J., Heiskanen, J., Aynekulu, E., \& Pellikka, P. K. E., 2015. Seasonal variation of land cover classification accuracy of Landsat 8 images in Burkina Faso. In: The International Archives of Photogrammetry, Remote Sensing and Spatial Information Sciences, Berlin, Germany, Vol: XL-7/W3, pp. 455-460.

Marangoz, A.M., Sekertekin, A. \& Akcin, H., 2017. Analysis of Land Use Land Cover Classification Results Derived From Sentinel-2 Image. 17th International Multidisciplinary Scientific GeoConference SGEM 2017, Albena, Varna, Bulgaria, pp. 2532.

Mejía, J.F., Hochschild, V., 2012. Land Use and Land Cover (LULC) Change in the Boconó River Basin, North Venezuelan Andes, and Its Implications for the Natural Resources Management. In: Environmental Land Use Planning. InTech, $244 \mathrm{p}$.

Pielke, R. A., Pitman, A., Niyogi, D., Mahmood, R., McAlpine, C., Hossain, F., Goldewijk, K. K., Nair, U., Betts, R., Fall, S., Reichstein, M., Kabat, P. and de Noblet, N., 2011. Land use/land cover changes and climate: modeling analysis and observational evidence. WIREs Clim Change, 2: 828-850.

Pirotti, F., Sunar, F., \& Piragnolo, M., 2016. Benchmark of Machine Learning Methods for Classification of a Sentinel-2 Image. In: International Archives of the Photogrammetry,
Remote Sensing \& Spatial Information Sciences, Prague, Czech Republic, Vol: XLI-B7, pp. 335-340.

Turner, M. G., Gardner, R. H., \& O'neill, R. V., 2001. Landscape ecology in theory and practice (Vol. 401). New York: Springer. 